\title{
PERFORMANCE EVALUATION OF CERAMICS MICROFILTRATION MEMBRANE FOR WATER TREATMENT
}

\author{
F.T. Owoeye ${ }^{1}$, A.P. Azodo ${ }^{1} *$ and S.B. Udo ${ }^{2}$ \\ ${ }^{1}$ Mechanical Engineering Department \\ Federal University of Agriculture \\ Abeokuta (FUNAAB),P M B 2240, Abeokuta, Nigeria. \\ E-mail: azodopat@gmail.com, lordphems2008@yahoo.com \\ Phone: +2348060601776 \\ ${ }^{2}$ Metallurgical Department, Yaba College of Technology \\ Yaba Lagos, Nigeria.P.M.B. 2011, Yaba, Lagos
}

\begin{abstract}
Ceramic membranes are especially suitable for processes with high temperatures and harsh chemical environments or for processes where sterilizability of the membrane is important. The main objective of this work is to determine the evaluation of four different ceramic membranes with different material compositions. Ceramic disc type microfiltration membranes were fabricated by the mould and press method from different percentage compositions of clay, kaolin, sawdust and wood charcoal. The fabricated membranes were sintered at a temperature of $1100^{\circ} \mathrm{C}$ and characterized by an $\mathrm{X}$-ray diffractometer and optical scanner. Compressibility tests and physical properties of the membranes were also examined. It was observed that, as the percentage composition of kaolin increased from 0 to $80 \%$ and the percentage composition of clay decreased from 80 to $0 \%$ respectively, the compressive stress of all the sample membranes increased, with an increase in compressive strain from 1.8 to 2.4. Sample A had the highest value of compressive stress from 1.8 to 2.2 compressive strain, but sample B had the highest value of compressive stress of $150 \mathrm{MPa}$ at a compressive strain of 2.4. Optical micrographs of all membranes showed the presence of uniformly distributed pores and no cracks were seen around them. It was concluded that, with increasing percentage of kaolin and decreasing percentage of clay, there was a decrease in porosity and water absorption, as well as a decrease in the mechanical properties of the fabricated membranes.
\end{abstract}

Keywords: Membranes; physical properties; X-ray diffractometer; kaolin; sintered.

\section{INTRODUCTION}

Ceramic membranes are especially suitable for processes with high temperatures and harsh chemical environments or for processes were sterilizability of the membrane is important. These ceramics were made of animal fat and bone mixed with bone ash and a fine claylike material. Primitive ceramics were made of basic earthen materials like clay and were burnt in domes. Ceramics is the materials science and engineering of inorganic or nonmetallic solids. Traditional ceramic raw materials include clay minerals such as kaolinite, aluminium oxide (alumina), carbides and silicates [1]. Membrane processes have been increasingly gaining importance in recent decades as separation techniques, since they offer several advantages over traditional methods (like precipitation or 
liquid-liquid extraction), such as set-up and handling simplicity, low time consumption, including a relatively cheap technology and they are environmentally respectful. Most membrane processes can be performed at room temperature and are carried out continuously. Furthermore, it must be considered that membranes can be prepared to have a wide range of different sizes from macro to micro. As a consequence, some membrane processes have already been applied at industry level; and certain of them, for instance, water treatment (including water desalination), food purification and biomedical purposes (blood dialysis), are even industrially consolidated [2-4]. Membranes may be divided, according to their composition, into organic or inorganic ones, the former (organic polymeric membranes) being mainly used in all commercial applications. Therefore, the discussion in this study essentially refers to polymeric membranes. A membrane applied for removing colloidal particles in liquid is usually semi-permeable. Its pore range of $0.1-20 \mu \mathrm{m}$ is suitable for water treatment, which allows one component of a mixture to permeate the membrane freely, while hindering permeation of other components $[5,6]$. The membrane separation process is based on the presence of semi-permeable membranes. The principle is quite simple; the membrane acts as a very specific filter that will let water flow through, while it catches small particles and other substances, where the performance is enhanced by the pressure difference, either applied pressure or vacuum. Membrane filtration can be used as an alternative to flocculation, sediment purification techniques, adsorption (sand filters and active carbon filters, ion exchangers, extraction and distillation) and sand $[2,7,8]$.

Microfiltration often serves as a critical step in ensuring final product integrity. Microorganism removal is essential to beverages in which contamination can lead to consumer illness, as well as to those beverages susceptible to microbial spoilage mechanisms. The microfiltration process uses porous membranes to separate suspended particles with diameters between 0.1 and $10 \mu \mathrm{m}[9,10]$. Beverages that are not in danger from microbial contamination may undergo microfiltration for general particulate removal to ensure the aesthetic quality of the final product. Microfiltration serves many auxiliary functions throughout the beverage industry in addition to final product filtration. Ensuring process water quality can be crucial to general plant cleaning and sanitation regimens. Gases such as carbon dioxide are being used in many product formulations. Bulk or point-of-use filtration of these gases is often important to maintaining product quality. Selective use of microfiltration can lead to a faster, easier, and more economical process. Brewers can use microfiltration both for lees recovery and as an alternative to pasteurization. Wineries may use microfiltration for titrate removal [11]. Whiskey makers can remove chill haze using a filtration step. Ceramic cross-flow systems allow the cleaning and reuse of caustic solution. Each plant's individual processes, even within the same industry, may have their own uses for microfiltration [12]. The bottled water and wine industries are the largest beverage microfiltration users in terms of spending. They are followed by the beer, spirits, and soft drink industries. Other industries that use microfiltration include juice, sports drink, energy drink, coffee and tea, oils, as well as various liquid or semi-liquid product or component producers. The ceramic membranes have found many applications in the food, beverage, biotechnological and pharmaceutical industries as well as in the petrochemical industry, environmental control, electronic industry, gas separation and other process industries [2, 13-17]. Ceramics are the most compatible products with their qualities of being free from decay caused by gradual natural impacts like corrosion, erosion, abrasion and thermal shocks [18]. Advantages of ceramic membranes include stability towards high temperature, high pressure and resistance to 
chemical attack $[19,20]$. It is commonly agreed that the key factor for the correct development and application of polymeric membranes is the control of their polymeric morphology. Therefore, many efforts have been made within recent decades to find the relationship between membrane preparation, membrane morphology and membrane performance [11]. In that sense, membrane characterization has become fundamental for the optimization of membrane process design, as membrane features, such as nature, thickness and porosity, govern the process behaviour. The best results, that is, the most unfailing outputs, are encountered when combining different membrane characterization techniques [21]. This research work is aimed at the determination and evaluation of four different ceramic membranes with different material compositions. It also focuses on the fabrication of membranes from natural raw materials, as well as the investigation of mechanical and physical properties of the produced membrane discs.

\section{MATERIALS AND METHOD}

The raw materials that were used for this research work are represented in Figure 1. The major materials constituents were clay and kaolin, while sawdust acted mainly to aid the porosity of the membranes and was burnt off during firing. Wood charcoal also gave room for little porosity, but mainly helped the fabricated membrane to be fired. Water was added to make paste. Table 1 shows the percentage composition of the raw materials used in fabrication of the membranes. Four membranes of different constituents were produced: sample A contained $80 \%$ clay, $0 \%$ kaolin, $10 \%$ sawdust and $10 \%$ charcoal. Sample B contained clay, kaolin, sawdust and charcoal at $60 \%, 20 \%$, $10 \%$ and $10 \%$ respectively. Sample C contained $20 \%$ clay, $60 \%$ kaolin, $10 \%$ sawdust and $10 \%$ charcoal, while sample D contained $80 \%$ kaolin, $10 \%$ sawdust, and $10 \%$ charcoal with no clay content.

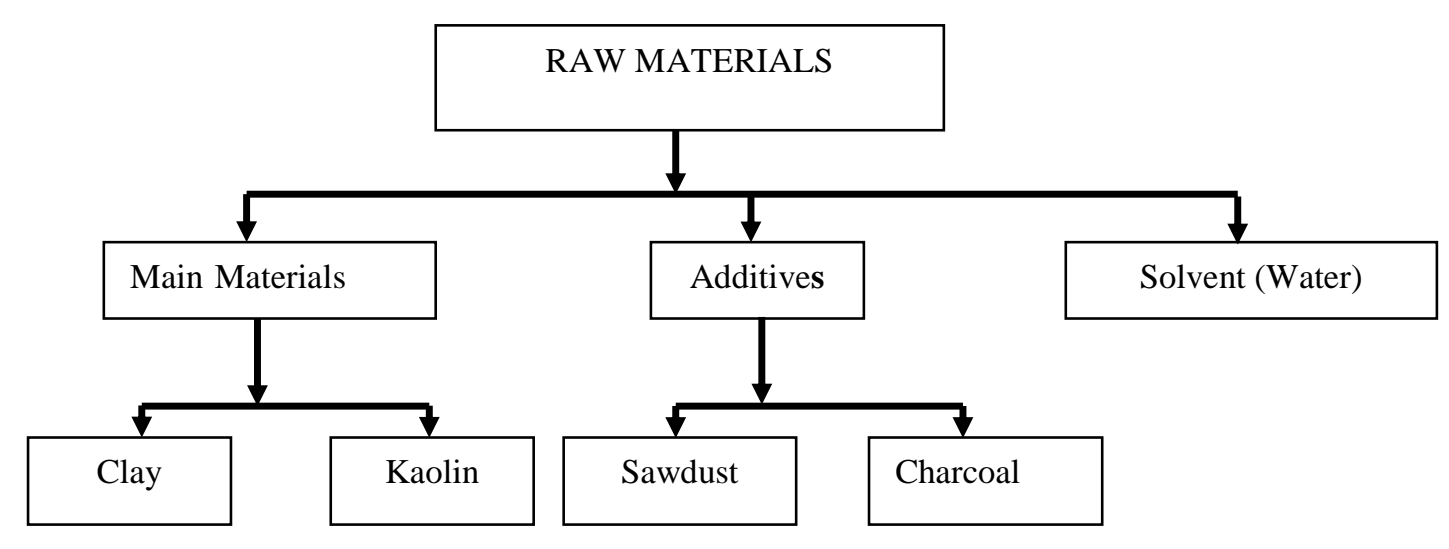

Figure 1.Graphical representation of the raw materials.

Table 1.Percentage composition of the raw materials.

\begin{tabular}{lllll}
\hline Samples & Clay \% & Kaolin \% & Sawdust $\%$ & Charcoal \% \\
\hline A & 80 & 0 & 10 & 10 \\
B & 60 & 20 & 10 & 10 \\
C & 20 & 60 & 10 & 10 \\
D & 0 & 80 & 10 & 10 \\
\hline
\end{tabular}




\section{Steps in Production of Membrane}

Slurry preparation: The main components of slurry used for the fabrication of ceramic membranes are inorganic powder, organic additives and solvent. In the selection of the inorganic powder, important factors are particle size and distribution, as well as the shape of the particles. They have an effect on the porosity, pore size and pore size distribution of the final product.

Grinding: This involves the process of breaking the large particles of raw materials into small pieces.

Milling: Milling is the process by which materials are reduced from a large size to a smaller size. Milling may involve breaking up cemented material (in which case individual particles retain their shape) or pulverization (which involves grinding the particles themselves to a smaller size). Milling is generally done by mechanical means, including attrition.

Sieving: A process by which un-milled materials are separated from fined/powder forms.

Batching: Batching is the process of weighing the raw materials according to their recipes and preparing them for mixing, weighing different powdered raw materials in different percentages to make up the batch composition for different membranes.

Mixing: Mixing occurs after batching and is performed with various machines such as dry mixing ribbon mixers [22].

Addition of water: Water is added to the mixed powders gradually in order to avoid over-softening of the contents.

Fabrication: Four pair membranes were fabricated by means of mould and press methods. The produced membranes were dried for some days and later sintered at a temperature of $110^{\circ} \mathrm{C}$. Details of the processing steps of the membranes are displayed in Figure 2.

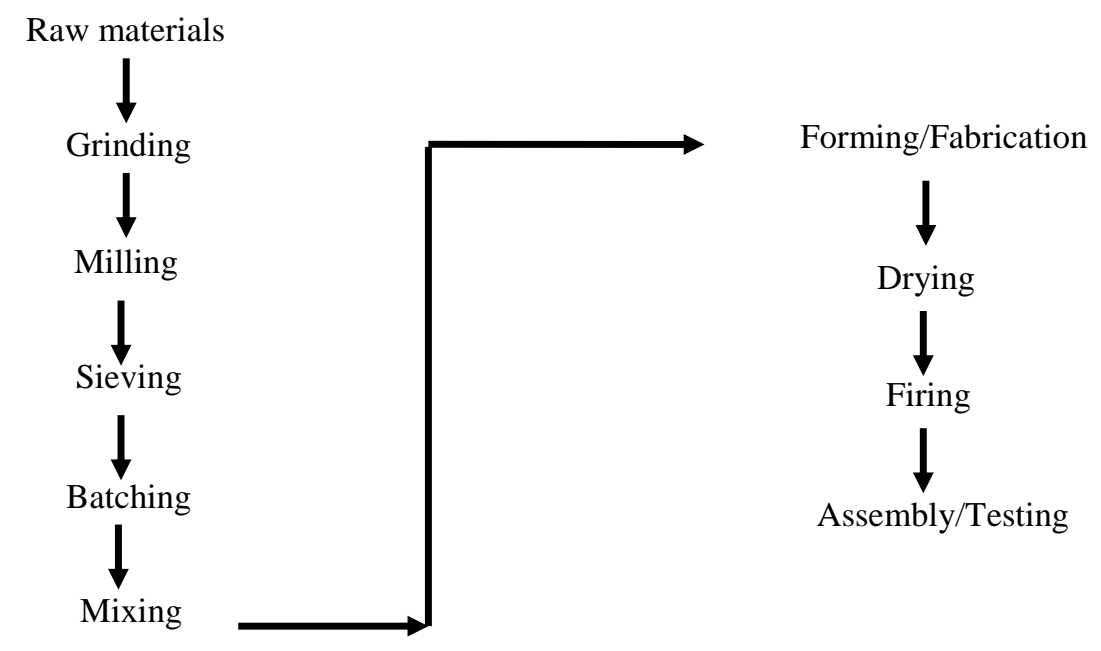

Figure 2. Sequential path for membranes preparation/production. 


\section{Determination of Mineral Composition of the Membranes}

The minerals compositions of all powder samples were determined in the laboratory of the Research Institute, Engineering Materials and Development Institute, Abeokuta, Nigeria. The mineralogical data were determined on each sample powder using Radicon MD-10, version 2.00 X-ray diffractometry equipment withCuK $\alpha$ radiation at exposure time of 1200/1200 seconds with Lambda: 1.5418 and a Beta filter used for all the samples. The diffractometer is an apparatus used to determine the angles at which diffraction occurs for powdered samples.

\section{Optical Testing}

The micrographs of all the fired samples were determined by an optical testing machine with model number 702907.

\section{Determination of Physical Properties of the Membranes}

\section{Bulk Density}

The bulk density of the fired membrane samples was determined by displacement of water from the beaker using the Archimedes principle. The weights of all membrane samples were measured in air using a Digital Electronic Scale model JCS-A Gallenkomp. The experimental set-up included the mass of the beaker partially filled with water, with and without the cut-up samples immersed in water one after the other. The difference gave masses of water displacement, according to the Archimedes principle. The mass of water displaced can be easily related to the volume of water displaced, as the density of water is known as $1000 \mathrm{~kg} / \mathrm{m}^{3}$. Thus, the bulk density in $\mathrm{g} / \mathrm{cm}^{3}$ is given in terms of mass sample measured in air and the volume displaced by the membrane as shown in Eq. (1).

$$
\text { Bulk density }(\mathrm{g} / \mathrm{ml})=\frac{\text { Massin air }(\mathrm{g})}{\text { Volume of water displaced }(\mathrm{ml})}
$$

\section{Percentage of Water Absorption by the Membranes}

Water absorption measurements were carried out according to BS EN 12808 - 5: (2008). Cut-up samples of fired membrane were measured using a Digital Electronic Scale model JCS-A Gallenkomp as initial weights of the membranes. The measured membrane samples were then soaked in water in a beaker for 24 hours at room temperature in the Mechanical Engineering laboratory. As the samples were immersed in water, air bubbles were observed as the pores in the samples were filled with water. After the lapsed time, the samples were removed from the beaker and allowed to dry by removing the excess water on the surfaces using a dry napkin prior to weighing as wet weight, and the percentage of water absorption was calculated as shown in Eq. (2).

$$
\text { Water absorption }(\%)=\frac{\text { Wet mass }(\mathrm{g})-\text { Massin air }(\mathrm{g})}{\text { Massin air }(\mathrm{g})} \times 100
$$




\section{Percentage Apparent Porosity of the Membranes}

For calculation of the percentage apparent porosity, all the samples were measured in order to get the initial weight (weight in air). They were suspended in water individually with string and air bubbling was observed. The weight of each suspended sample was measured. The samples were also soaked in water for 24 hours, after which the weights were measured. The percentage apparent porosity was determined as shown in Eq. (3):

$$
\operatorname{Apparentporosity}(\%)=\frac{\text { Soaked mass }(\mathrm{g})-\text { Massin air }(\mathrm{g})}{\text { Soaked mass }(\mathrm{g})-\text { Suspended mass }(\mathrm{g})} \times 100
$$

\section{RESULTS AND DISCUSSION}

\section{Chemical Composition of Clay}

From the percentages of chemical composition of the clay material, alumina and silica are found to be the major constituents with other minor constituents, while the percentage of manganese (II) oxide [23] could not be determined. The loss on ignition (LOI) corresponds to water vapour from hydroxide reaction in the clay minerals, the burning out of organic matter and the carbonate decomposition in $\mathrm{CO}_{2}$ and oxide in the minerals, as shown in Table 2.

Table 2.Chemical composition of clay.

\begin{tabular}{lccccccccccc}
\hline $\begin{array}{l}\text { Clay } \\
\text { contents }\end{array}$ & $\mathrm{SiO}_{2}$ & $\mathrm{TiO}_{2}$ & $\mathrm{Al}_{2} \mathrm{O}_{3}$ & $\mathrm{Fe}_{2} \mathrm{O}_{3}$ & $\mathrm{MnO}$ & $\mathrm{MgO}$ & $\mathrm{CaO}$ & $\mathrm{P}_{2} \mathrm{O}_{5}$ & $\mathrm{~K}_{2} \mathrm{O}$ & $\mathrm{Na}_{2} \mathrm{O}$ & $\mathrm{LOL}$ \\
\hline $\begin{array}{l}\text { Composition } \\
\%\end{array}$ & 46.4 & 1.69 & 34.0 & 2.49 & $\mathrm{ND}$ & 0.04 & 0.02 & 0.04 & 0.08 & 0.03 & 17.7 \\
\hline
\end{tabular}

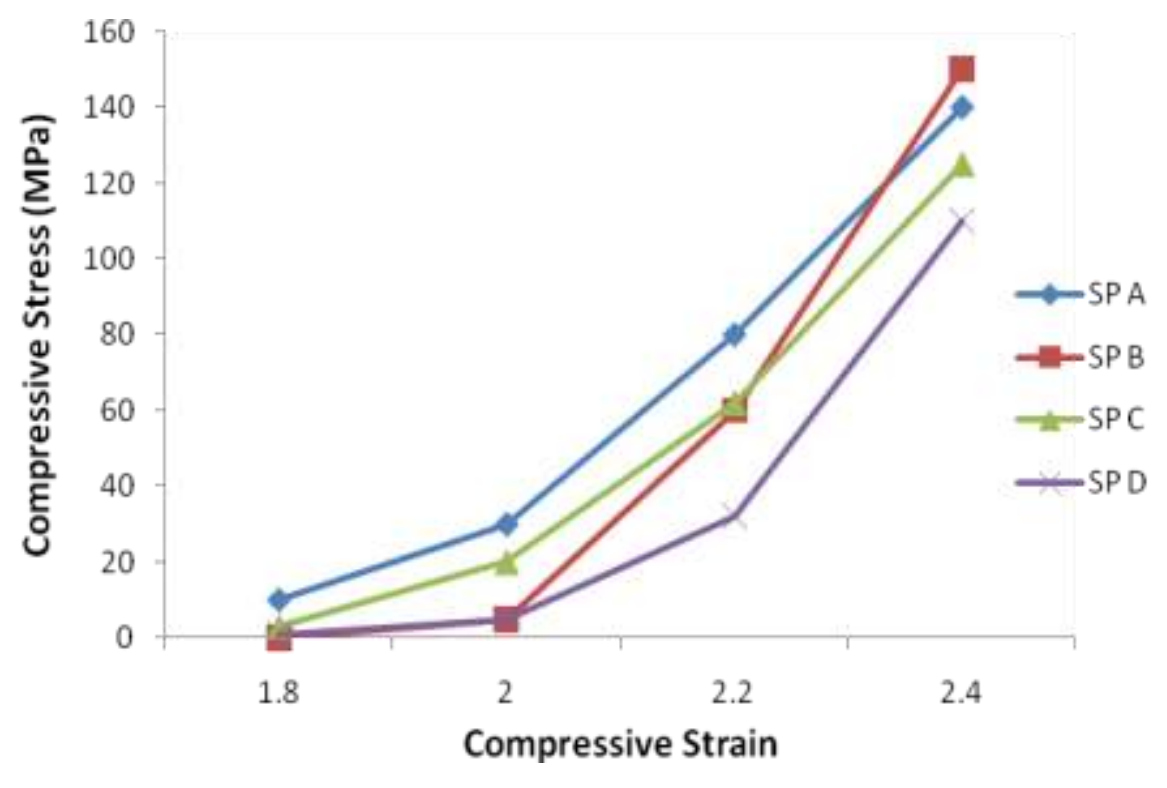

Figure 3. Compressive stress against compressive strain. 


\section{Compressibility Test}

Figure 3 shows the compressive stress against compressive strain of the produced membranes. Generally, the compressive stress of all the sample membranes increased with increase in compressive strain from 1.8 to 2.4. Sample A had the highest value of compressive stress at 1.8 to 2.2 compressive strain, but sample B attained the highest overall value of compressive stress of $150 \mathrm{MPa}$ at compressive strain of 2.4 . The relationship between compressive stress and strain showed that the fabricated membranes have the ability to withstand external loads during the operation that is the filtration technique [24].

\section{Physical Properties of the Membranes}

The apparent porosity of the membranes examined, as shown in Table 3, decreased from samples A, B, C to D with values of $170.05,165.71,161.9$ and $153.10 \%$ respectively. The water absorption of the membranes also decreased in value from samples A to D in a narrower range (48.92 to $46.52 \%)$. Bulk densities of the fabricated membranes increased from samples A, B, C to Dwith values in order of 33.01, 34.09, 34.93 and $35.82 \mathrm{~g} / \mathrm{ml}$.

Table 3. Apparent porosity of the membranes.

\begin{tabular}{llll}
\hline Samples & Apparent porosity $(\%)$ & Water absorption $(\%)$ & Bulk density $(\mathrm{g} / \mathrm{ml})$ \\
\hline SP A & 170.05 & 48.92 & 33.01 \\
SP B & 165.71 & 48.56 & 34.09 \\
SP C & 161.9 & 47.11 & 34.93 \\
SP D & 153.10 & 46.52 & 35.82 \\
\hline
\end{tabular}

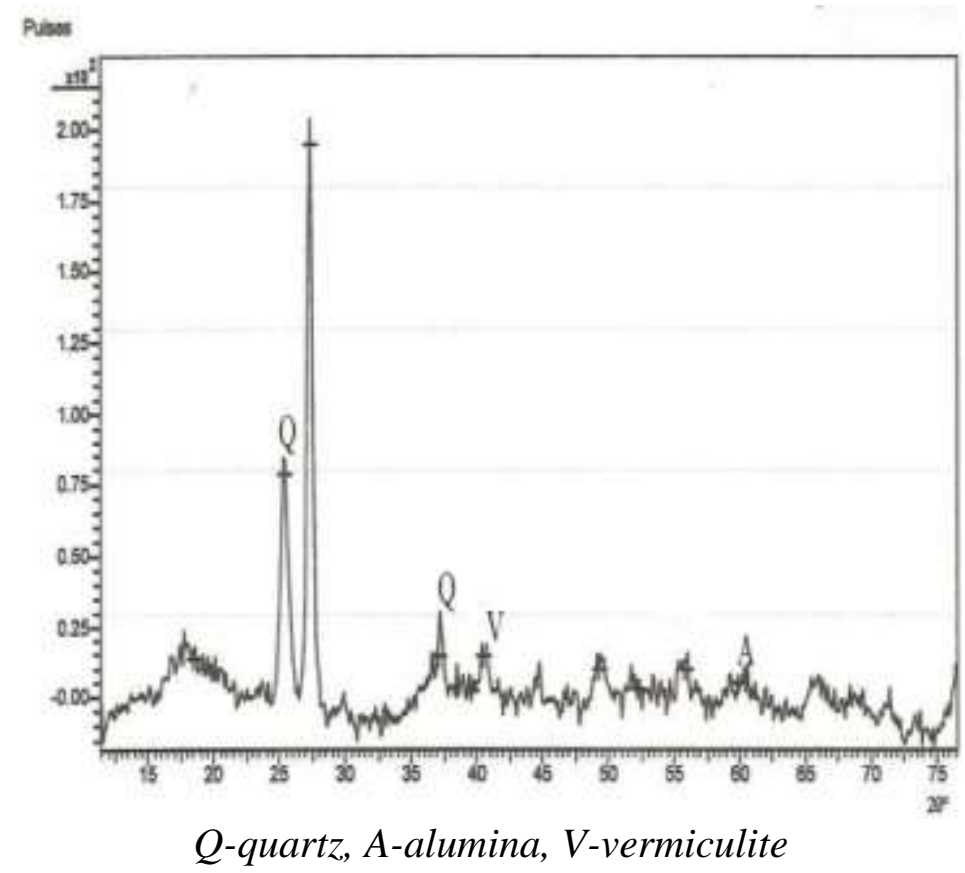

Figure 4. X-ray diffraction pattern for membrane A. 


\section{Mineral Compositions of Membranes}

The crystalline phases in the fired fabricated membranes, as shown in Figures 4 to 7 , were identified using an X-ray diffractometer, a Radicon MD10.00UM, Version 2.00.1 using $\mathrm{CuK} \alpha$ radiation at $40 \mathrm{Kv} / 40 \mathrm{~mA}$ from $12^{\circ}<2 \theta<73^{\circ}$, with exposure time of $1200 / 1200$ sec. Figure 4 shows the diffraction pattern for membrane A containing quartz, alumina and vermiculite. In quartz, it had the highest peak of $0.75 \times 10^{2}$ pulses and $25.0^{\circ}$ at $2 \theta$, while the vermiculite had a peak of $0.2 \times 10^{2}$ pulses and $40.0^{\circ}$ at $2 \theta$. Alumina had its highest peak of $0.1 \times 10^{2}$ pulses and $60.0^{\circ}$ at $2 \theta$. Alumina, montmorillonite, quartz, vermiculite and silica are the minerals contained in membrane B, as shown in Figure 5. Alumina and quartz had their highest peaks of $0.1 \times 10^{2}$ pulses and $40.0^{\circ}$ at $2 \theta$ and $0.3 \times 10^{2}$ pulses and $17.5 .0^{\circ}$ at $2 \theta$ respectively. Montmorillonite had its highest peak of $0.25 \times 10^{2}$ pulses and $55.0^{\circ}$ at $2 \theta$, while vermiculite had its highest peak of $0.25 \times 10^{2}$ pulses and $65.0^{\circ}$ at $2 \theta$. The highest peak of $0.25 \times 10^{2}$ pulses and $37.5 .0^{\circ}$ at $2 \theta$ was produced by silicate. Figure 6 shows the diffraction pattern of fabricated membrane $C$, which contained quartz and kaolin. Kaolin had its highest peak of $0.7 \times 10^{2}$ pulses and $17.7^{\circ}$ at $2 \theta$, while the quartz had the highest peak of $0.25 \times 10^{2}$ pulses and $20.0^{\circ}$ at $2 \theta$. Figure 7 shows that the diffraction pattern for membrane $\mathrm{D}$ contained the presence of kaolin and carbon with highest peaks of $1.3 \times 10^{2}$ pulses and $25.0^{\circ}$ at $2 \theta$ and $0.3 \times 10^{2}$ pulses and $36.0^{\circ}$ at $2 \theta$. It also contained vermiculite and montmorillonite [25].

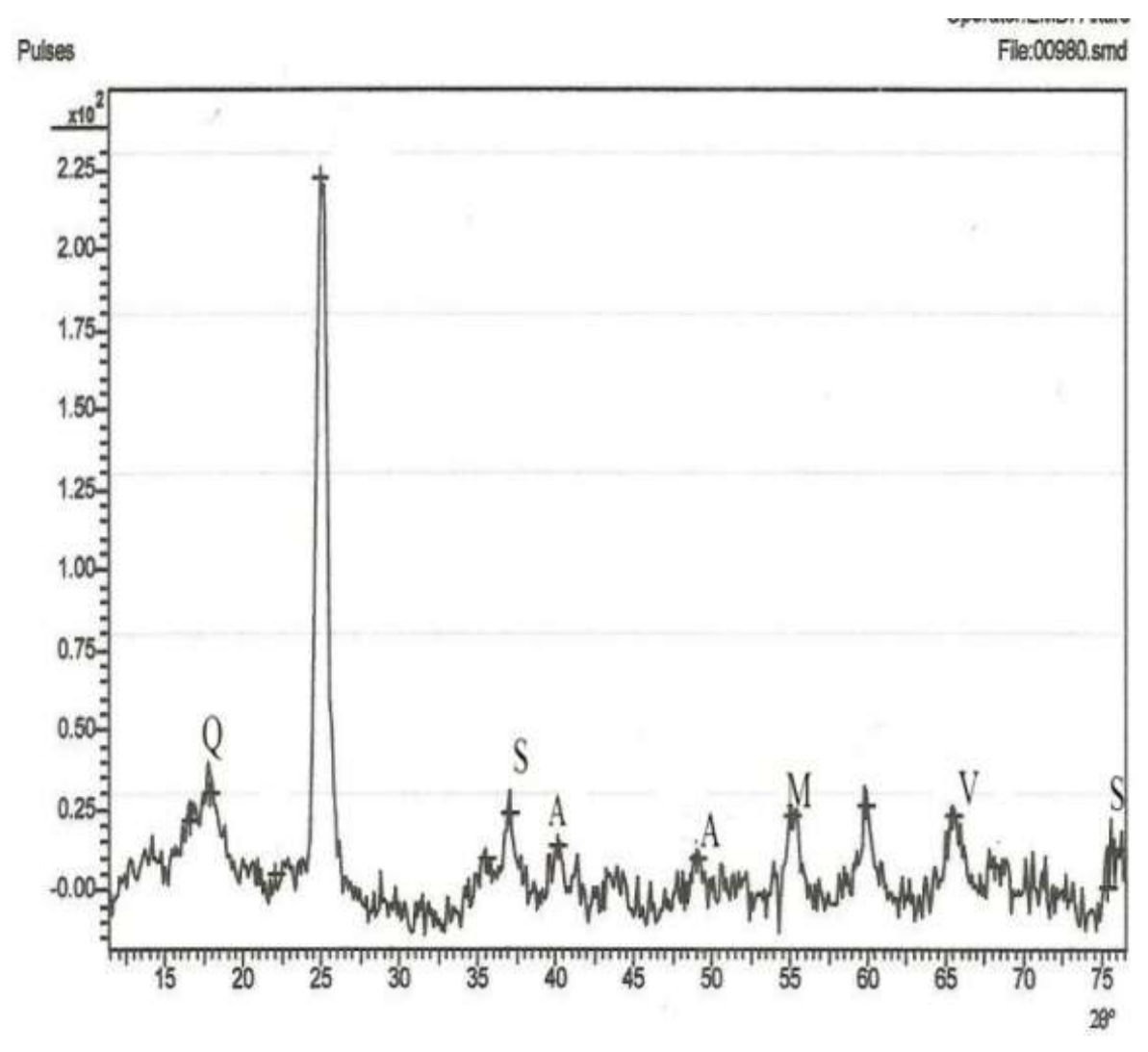

A-alumina, M-montmorillonite Q-quartz, V-vermiculite, S-silica

Figure 5. X-ray diffraction pattern for membrane B. 


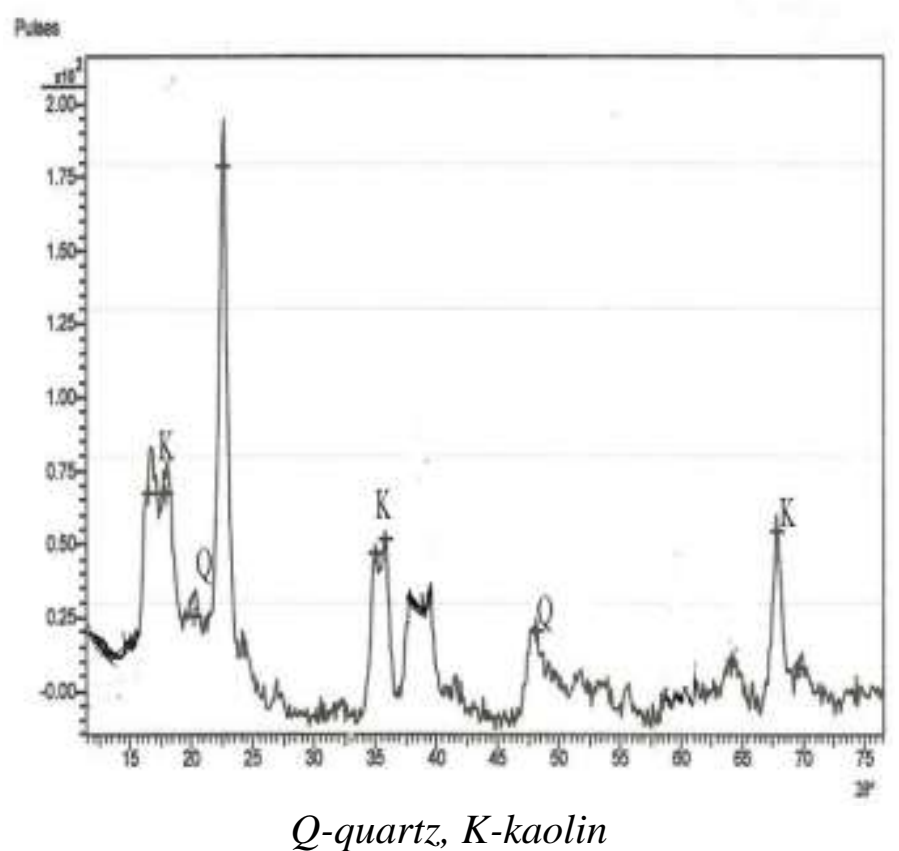

Figure 6. X-ray diffraction pattern for membrane C.

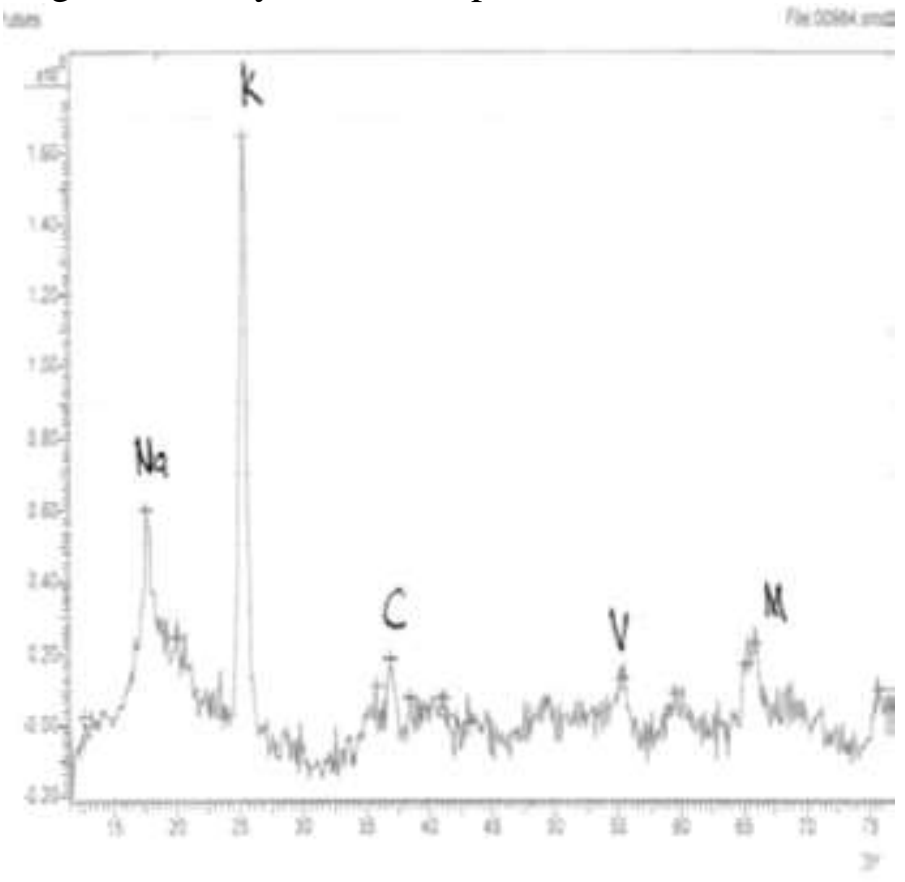

K-kaolin, $C$-carbon, $V$-vermiculite, $M$-montmorillonite

Figure 7. X-ray diffractometer pattern for membrane D.

\section{Optical Micrographs of the Membranes}

Figure 8 shows the optical micrographs of the four fabricated membranes A, B, C and D respectively, with the lens of the machine set at a magnification of 100. It was noticed generally in all the four membranes that the magnifications of 100 were dark. It was also observed that all the membrane surfaces were neat, without any traces of cracks. 


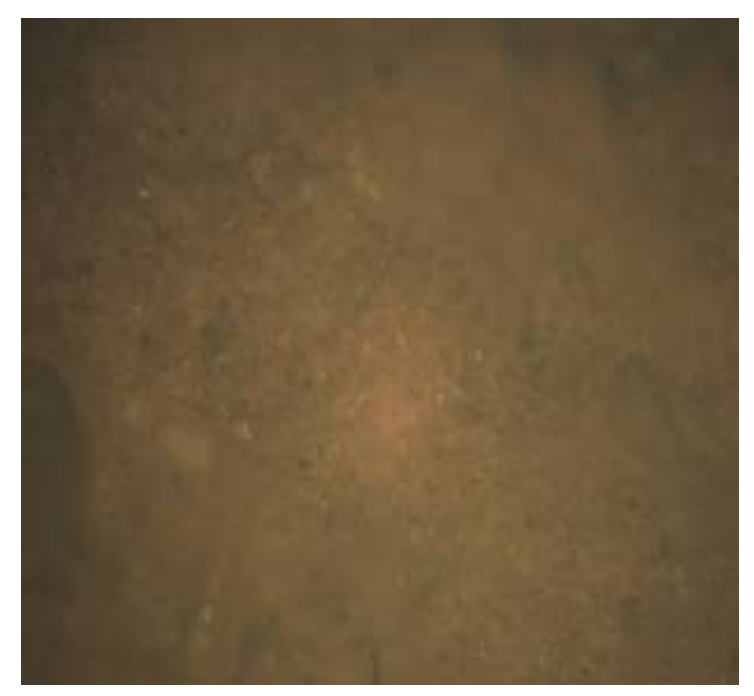

M: X100

(a) Membrane A

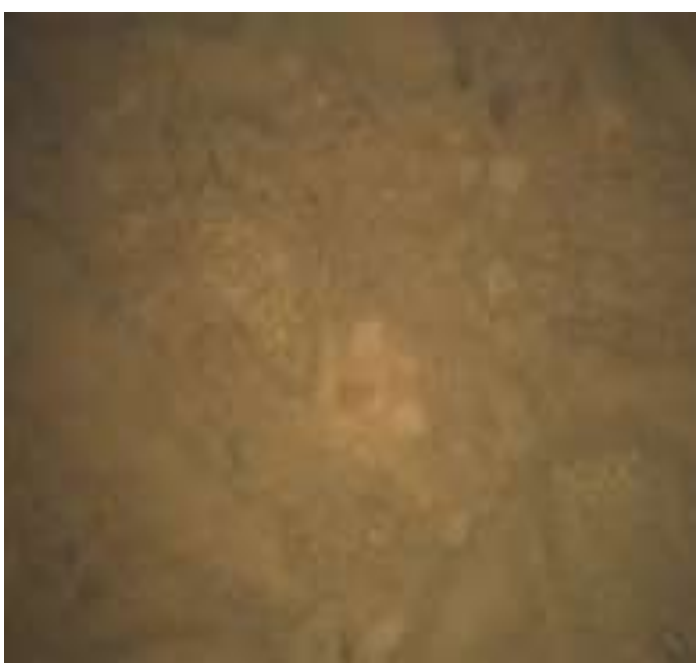

M: X100

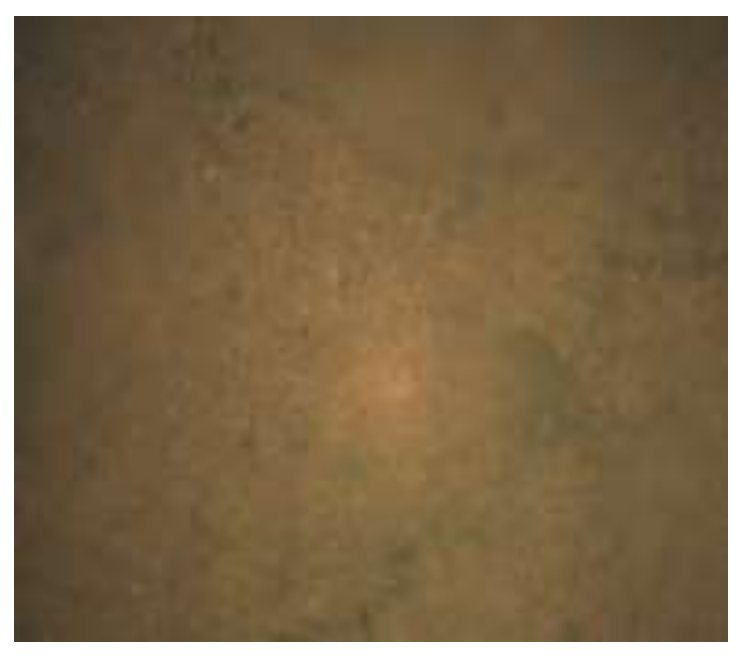

M: X100

(b) Membrane B

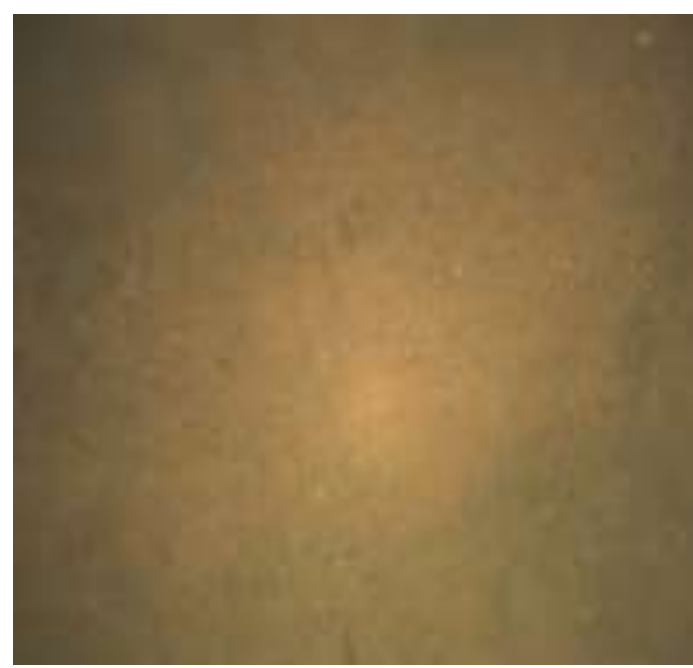

M: X100

(d) Membrane D

Figure 8. Optical micrograph

\section{CONCLUSIONS}

This research work has been able to make use of natural resources or raw materials that are highly available with low cost of extraction from their natural deposits. The total cost of production of these membranes is much less than procuring synthetic or already made materials for the production of membranes that perform the same function. Also, this project work has enabled us to fabricate effective and functional membranes from different constituents of raw materials for water treatment. The optical micrographs of all the membranes showed the good quality of the clay and kaolin materials used in the production of the membranes, as there were no cracks on any of the membranes, despite 
the high firing temperature of $1100^{\circ} \mathrm{C}$. The addition of kaolin content in the mixture of all the sample membranes prepared reduced the physical properties of the percentage of porosity and that of water absorption, while only the bulk density of the sample membranes increased with an increase in the percentage of kaolin content. It was concluded that, with an increasing percentage of kaolin and a decreasing percentage of clay, there was a decrease in porosity and water absorption, as well as a decrease in the mechanical properties of the fabricated membranes. Further research should be carried out to investigate the performance of ceramic nano-filtration membranes for water treatment.

\section{ACKNOWLEDGEMENTS}

Our special gratitude to the entire staff of the Mateng Water Filtron Abeokuta for allowing us to make use of their equipment for the fabrication of the membranes.

\section{REFERENCES}

[1] Chiang Y-M, Birnie DP, Kingery WD. Physical Ceramics: Principles for Ceramic Science and Engineering. USA: John Wiley \& Sons, Inc.; 1997.

[2] Malik AA, Kour H, Bhat A, Kaul RK, Khan S, Khan SU. Commercial utilization of membranes in food industry. International Journal of Food Nutrition and Safety. 2013;3:147-70.

[3] Kelvin H, Ramesh S, Tan CY, Teng WD. Phase analysis and densification of steatite-based ceramics. International Journal of Automotive and Mechanical Engineering. 2010;1:38-45.

[4] Mousharraf A, Islam MF. Effect of Ta2O5 doping on the microstructure and dielectric properties of $\mathrm{BaTiO} 3$ based ceramics. International Journal of Automotive and Mechanical Engineering. 2013;7:840-9.

[5] Baker RW. Membrane technology: Wiley Online Library; 2000.

[6] Ramesh S, Tan CY, Amiriyan M, Teng WD. Sintering effects on the densification of nanocrystalline hydroxyapatite. International Journal of Automotive and Mechanical Engineering. 2011;3:249-55.

[7] Ashaghi KS, Ebrahimi M, Czermak P. Ceramic ultra- and nanofiltration membranes for oilfield produced water treatment: A mini review. The Open Environmental Journal. 2007;1:1-8.

[8] Shivajirao PA. Treatment of distillery wastewater using membrane technologies. Int J Adv Eng Res Stud. 2012;1:275-83.

[9] DT. Desalination Technologies (DT). 2008.

[10] Wakeman R, Williams C. Additional techniques to improve microfiltration. Separation and Purification Technology. 2002;26:3-18.

[11] Mueller U, Witte M. Ceramic membranes-Case related protocol for optimal operational conditions to treat filter backwash water. Techneau. 2007;51:221-9.

[12] Chilcott T, Chan M, Gaedt L, Nantawisarakul T, Fane A, Coster H. Electrical impedance spectroscopy characterisation of conducting membranes: I. Theory. Journal of Membrane Science. 2002;195:153-67.

[13] Bhave RR. Inorganic membranes synthesis, characteristics, and applications: Springer; 1991.

[14] Stratton J. Membrane separation technology in the food industry. Filtration \& Separation. 1999; 41(8), 32-33.. 
[15] Chou C, Iqbal K, Min Y, Gao D, Duffault E. White and refined sugar production from cane sugar factories. Proceedings of First Biennial World Conference on Recent Developments in Sugar Technologies. 2002; 5.

[16] Lipnizki F, Carter M, Tragardh G. Applications processes in the beet and cane sugar production. Zuckerindustrie. 2006;131:29-38.

[17] Rektor A, Vatai G. Application of membrane filtration methods for must processing and preservation. Desalination. 2004;162:271-7.

[18] Kingery W, Bowen H, Uhlmann D. Introduction to Ceramics. 2nd ed. New York: Wiley; 1976.

[19] Maiti HS. Iron removal plant-based CGCRI technology. Dimapur, Nagaland; 2006.

[20] Meabe E, Lopetegui J, Ollo J, Lardies S. Ceramic membrane bioreactor: potential applications and challenges for the future. Spain: CEIT Technological Center. p. 1-9.

[21] Güell C, Ferrando M, López F. Monitoring and visualizing membrane-based processes: John Wiley \& Sons; 2009.

[22] Brinker CJ, Scherer GW. Sol-gel science: the physics and chemistry of sol-gel processing. New York: Academic Press; 1990.

[23] Prosser D, Basrai T, Dickert J, Ratti J, Crassidis A, Vachtsevanos G. Wing kinematics and aerodynamics of a hovering flapping micro aerial vehicle. Aerospace Conference, IEEE. 2011; 1-10.

[24] Flores OJ, Andrade FA, Hotza D, Al-Qureshi HA. Modeling of plasticity of clays submitted to compression test. World Academy Science, Engineering and Technology. 2010;61:191-6.

[25] Birkholz M, Genzel C, Jung T. X-ray diffraction study on residual stress and preferred orientation in thin titanium films subjected to a high ion flux during deposition. Journal of Applied Physics. 2004;96:7202-11. 